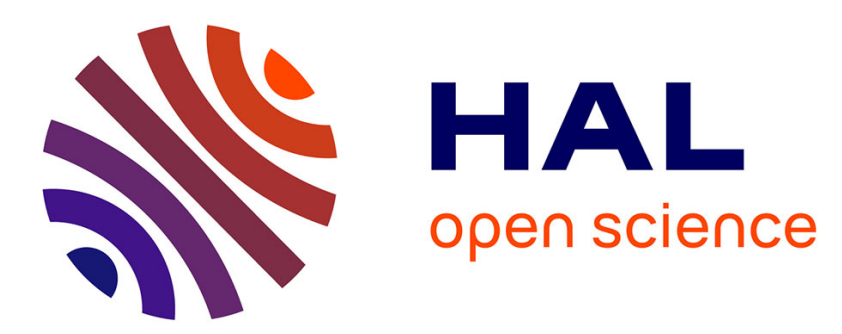

\title{
The emergence of the social-ecological restoration concept
}

Juan Fernández-Manjarrés, Samuel Roturier, Anne-Gaël Bilhaut

\section{To cite this version:}

Juan Fernández-Manjarrés, Samuel Roturier, Anne-Gaël Bilhaut. The emergence of the socialecological restoration concept. Restoration Ecology, 2018, 26 (3), pp.404-410. 10.1111/rec.12685 . hal-02390584

\section{HAL Id: hal-02390584 https://hal.science/hal-02390584}

Submitted on 3 Dec 2019

HAL is a multi-disciplinary open access archive for the deposit and dissemination of scientific research documents, whether they are published or not. The documents may come from teaching and research institutions in France or abroad, or from public or private research centers.
L'archive ouverte pluridisciplinaire HAL, est destinée au dépôt et à la diffusion de documents scientifiques de niveau recherche, publiés ou non, émanant des établissements d'enseignement et de recherche français ou étrangers, des laboratoires publics ou privés. 
7 Juan F. Fernández-Manjarrés ${ }^{1,3}$ Samuel Roturier $^{1}$, Anne-Gaël Bilhaut ${ }^{2}$

8

$9{ }^{1}$ Ecologie, Systématique Evolution, CNRS-AgroParisTech-Univ. Paris Sud, Université Paris

10 Saclay, F-91405, Orsay, France

11 '2nstitut Français d'Etudes Andines, Quito, Ecuador

$12 \quad 3$ Corresponding author, juan.fernandez@u-psud.fr

13

14 Author contributions

15 JFM conceived and designed the study; AGB contributed the study case with Amazonian

16 Ecuador communities; JFM, AGB, SR wrote and edited manuscript.

17 


\section{Abstract}

Many ecosystems in the world are the result of a close interaction between local people and their

21 environment, which are currently recognized as social-ecological systems (SoES). Natural

22 catastrophes or longstanding social and political turmoil can degrade these SoES to a point where

23 human societies are no longer autonomous and their supporting ecosystems are highly degraded.

24 Here we focus on the special case of the restoration of SoES that we call social-ecological 25 restoration (SoER), which is characterized as a restoration process that cannot avoid 26 simultaneously dealing with ecological and social issues. In practice, SoER is analogous in many 27 ways to the general principles of ecological restoration, but it differs in three key aspects: 1) the 28 first actions may be initially intended for human groups that need to recover minimum living 29 standards; 2) the SoER process would often be part of a healing process for local people; and 3) there is a strong dependency on external economic inputs, as the people belonging to the SoES

31 may be incapable of reorganizing themselves on their own and supporting ecosystems can no 32 longer self-recover. Although it might not be desirable or necessary to call all restoration projects with a social component a SoER, the use of this concept may help in defining early restoration 34 targets that may prevent conflicts among users in the long term. From the perspective of other 35 disciplines and humanitarian institutions, SoER would be more appropriately perceived as 36 programs of 'social-ecological recovery' or 'social-ecological development'. 


\section{Implications for Practice}

42 - Social-ecological restoration (SoER) cycles may involve several very difficult decisions between human well-being and ecosystem recovery for which many managers may feel overwhelmed. Hence, managers should reach for extended collaboration beyond their usual disciplines and institutions.

- Natural catastrophes may set ecosystems in trajectories for which people dependent on them may not be able to cope with. Open minds and a dynamic view of ecosystems are therefore needed for a successful SoER

- Resources need to be wisely allocated in SoER as social dynamics can be very fast while ecosystem dynamics may be beyond human generation times 


\section{Introduction}

55 Reconciling ecological restoration goals with human well-being objectives is a restoration 56 approach that needs no further presentation in the ecological sciences. The link between the two

57 has been actively tackled through the ecosystem services concept, with various review articles 58 suggesting the links between restored diversity and ecosystem function on the one hand, and the 59 availability of ecosystem services on the other (Benayas et al. 2009; Alexander et al. 2016). The underlying hypothesis is that if restoration re-enables ecosystems services while maintaining and

61 promoting biodiversity, human needs are met in a "win-win" scenario and may even help to 62 alleviate poverty (Cao et al. 2009; Aronson et al. 2010 and references therein; Cao 2011; Yin \& Zhao 2012). A related approach used to address the relation between ecological and social issues

64 in restoration has been to include traditional knowledge in restoration programs (e.g., Uprety et al. 2012). However, an ecosystem service-centered approach to restoration and conservation goals has been also criticized on the grounds that it can lead to a loss of biodiversity and ecosystem

67 functions in the long term without really solving the social issues they were supposed to (Blignaut \& Aronson 2008; Vira \& Adams 2009; Schroter et al. 2014; Batavia and Nelson 2017). Hence,

69 there is a need to maintain a diversity of views regarding the relation between people and 70 ecosystems when social and economic concerns are pressing.

Here we argue that under certain circumstances, a common goal of social and ecological

72 reparative measures can be explicitly named 'social-ecological restoration' provided that the goal

73 is to restore a 'social-ecological system'. By social-ecological system, we understand a complex

74 system that has emerged through a series of people's close interactions with their supporting

75 ecosystems and species, creating structures and processes that would otherwise not exist. Only 76 until recently has the scientific literature begun to explicitly address the concept of social- 
77 ecological restoration as both a practice and a conceptual field in itself. To the best of our

78 knowledge, the term was coined recently by Takeuchi and collaborators in an article addressing

79 the need for a comprehensive approach to reconstruct the areas devastated by the 2011 earthquake,

80 ensuing tsunami, and radioactive pollution in northeastern Japan (Takeuchi et al. 2014).

81 In contrast to the ecological sciences, the social sciences and organizations that deal with

82 humanitarian crises do not use the word restoration. Instead, the term 'recovery' is more commonly

83 used, but mostly as part of a 'recovery plan' for countries torn down by war or natural catastrophes

84 (UNDG 2007). The expression 'social restoration' is not used in the social sciences, because it

85 would be a controversial concept for obvious reasons, including undesirable political

86 interpretations. Societies and cultures are not restored as no one would intend to return exactly to

87 past cultural values or practices. It is well accepted that cultures change and that each epoch has

88 its own set of shared values that will evolve over time. Nevertheless, the expression 'social

89 restoration' has been used sporadically by urban planners in the context of how ecological

90 restoration should be socially acceptable and not lead to conflicts with users (Eden \& Tunstall

91 2006; Nagendra \& Ostrom 2014). Thus, it would appear that Takeuchi and colleagues' use of

92 social-ecological restoration is the first attempt to clearly interlink social and ecological goals in

93 the reconstruction of societies and their supporting ecosystems.

94 Here we propose that social-ecological restoration (SoER) is a problem-solving approach

95 in which the main goal is to jointly restore the interdependent social and ecological processes in a

96 social-ecological system (SoES). We believe that this concept and practice are probably more

97 adapted to areas in which the historically strong presence of humans has shaped the terrestrial

98 landscapes, wetlands, and coastal areas and in which present-day human populations struggle to

99 have a sustainable society. We discuss throughout the text how this approach differs from 
ecosystem-service centered restoration and present some practical issues related to the emergence of the SoER concept by presenting a parallel with humanitarian crises and a case study from the Shuar communities in Ecuador.

\section{Do we need a new concept?}

The short answer, in our opinion, is yes. Many readers will argue that they have already been working in social-ecological restoration and that the lack of a term has not prevented them from using both ecological and social approaches to deal with specific restoration cases, which we agree with. Yet the need to use a specific term, as with Takeuchi and collaborators, stems from at least three key points: 1) it permits an up-front dismantling of any animosity or ambiguity in a restoration program by setting clear goals from the onset that are well accepted by a majority of people; 2) it helps to identify quickly objects and processes that link the natural system and human societies at the proper geographical and temporal scales; and, most importantly, 3) it is a concept appropriate for societies that have suffered from natural disasters or long-term armed conflicts in which people have lost everything and supporting ecosystems are presently fragile.

Conflicts and animosity against restoration programs is not new, and it is one of the most recurrent issues (Geist \& Galatowitsch 1999; Buckley \& Crone 2008; Palamar 2010; Halme et al. 2013; Winkel 2014; Druschke \& Hychka 2015; Fox et al. 2016; Alves-Pinto et al. 2017). As stated previously by Geist and Galatowitsch (1999), there is a need to show and implement reciprocity in restoration programs so that people's contributions to the restoration of ecosystems are inversely compensated by the contributions of ecological restoration to people, which proves extremely challenging. In areas where there are close links between human societies and plant or animal populations, which represent the main resources of livelihood, programs framed as SoER 
123 may be better accepted by stakeholders. Humanitarian, post-conflict or post-catastrophe 124 management agencies and organizations will be obliged to look into ecosystem recovery, 125 something that is frequently overlooked because of the dimensions of the crisis (Abrahams 2014). 126 Evidently, the open use of the social-ecological restoration concept does not prevent all conflicts, 127 as unforeseen tensions may emerge at any time.

The SoER approach helps to identify early keystone objects and processes that would 129 otherwise be pondered differently or in later steps if only ecological or social analysis were 130 conducted. After a crisis, chances are that the affected society will very quickly point out what 131 essential components of the ecosystem are lacking and what processes have been disrupted that 132 they deem necessary to return back to their normal lives. In the case of the post-tsunami actions in 133 Japan, coastal forests (object 1) were identified as natural way to stabilize dunes (process 1) in 134 stark opposition to concrete barriers which would destroy the landscape. Likewise, inner riparian 135 broadleaf forests (object 2) were identified as a means to maintain good-quality water (process 2) 136 for oyster culture in the sea, which is an essential part of the human activities in the area (Takeuchi 137 et al. 2014), and so forth. This object-process based approach will also help to identify the 138 disciplines and expertise required to tackle problems at the social-ecological level in an 139 interdisciplinary way as this cannot be anticipated in advance. Whether forestry, aquaculture, 140 agronomical and even mining expertise is needed during the implementation of a humanitarian 141 program depends much of how people see themselves after crises (see next).

142 In our view, the use of SoER as a driving concept can prove particularly useful after natural 143 or human-induced disasters, because almost all natural and social processes and structures have 144 been disrupted. Moreover, as shown by Takeuchi and collaborators (2014) and in the example of 145 the recovery after Hurricane Katrina in the southeastern United States (for a review see Day et al. 
146 2007), reconstructing the links between people and natural processes can help in the healing

147 processes for the human populations. For instance, reconstructing the natural structure of the

148 Mississippi Delta will require new paradigms of development if the same catastrophes are to be

149 avoided in the future, and if a human environment that is culturally identified with living within

150 the wetlands is to be maintained. However, the SoER concept may be useful not only for regions

151 affected by large natural catastrophes, but also in places where longstanding conflicts and social

152 turmoil have erased people's capacity to manage and conserve their ecosystems (see example with

153 Amazonian communities in the last section). For example, international organizations have been

154 increasingly working with the restoration of degraded ecosystems due to overpopulation, poverty,

155 and war (see http://www.unep.org/disastersandconflicts/what-we-do/recovery/environmental-

156 cooperation-peacebuilding and UNEP 2016). While the expression of SoER has not been used in

157 these programs, the arguments are similar to what we propose here. In fact, the subjacent idea that

158 the good governance of resources is an essential way to prevent conflicts strengthens the concept 159 of SoER.

161 What is the scale of social-ecological restoration?

162 If the research or restoration object of SoER is the social-ecological system, then its spatial and

163 temporal scale corresponds to the SoES. As seen above, the general definition of SoES is open to 164 discussion regarding the relevant spatial scale, because it is difficult to trace limits in a globalized 165 economy. One response from institutional economics can help us to limit the scope of SoER. In 166 particular, the works of Elinor Ostrom and colleagues define the scale (or SoES itself) as the scale 167 at which people self-organize to use a given resource (Ostrom 2009). In the context of Ostrom's 168 works, 'resource' refers to provisioning ecosystem services such as irrigation water, timber, 
fisheries, and so on. This approach baffles the majority of ecologists who, for obvious reasons, 170 would argue that the spatial scale of the supporting ecosystem as the scale to consider. Hence,

171 SoER would need explicitly a step of negotiation between ecologists and social workers and

172 between the ecologists and funding agencies for the need to include a larger geographical area for

173 the implementation of restorative ecosystem measures. Again, this was clearly shown by Takeuchi

174 and collaborators when they addressed the need to work together on the mountain-plane interface 175 (satoyama) and on the shore-sea interface (satoumi) as integrated units that represent essential 176 components of their cultural heritage.

\section{People recovery, reference systems, and external inputs}

179 Solving humanitarian crises (EuropeAid 2004) and ecological restoration (McDonald et al. 2016) 180 share management principles of cycles of diagnostics, implementation and evaluation (Fig. 1, 181 Supporting Information Appendix S1). Restoration cycles, either ecological or humanitarian, are 182 necessarily sequential, incremental and each step has a duration that cannot be predicted. 183 Humanitarian aid is highly coded by international institutions and are defined at the scale of a 184 country even if the actions are local. Nevertheless, despite overall similarities between restoration 185 cycles and humanitarian aid cycles, key differences exist between ecological restoration and SoER 186 (Table S1). The first main difference is that in SoER the majority of resources would be used in 187 the initial stages of the restoration process to recover the minimum living standards for the people 188 concerned. This can be viewed as a social bias in the restoration process, but aside from the 189 humanitarian reasons, it actually may be a useful thing to relieve the pressures placed on the 190 supporting ecosystems before a complete SoER plan is being designed. 
Although the cultural values of ecosystems is of primary importance because SoER is 192 frequently part of a healing process, it is difficult to anticipate how much of the previous ecosystem 193 will be desired by the people. The second and perhaps greatest challenge in SoER, at least from 194 the perspective of the ecological sciences, is agreeing on the reference system to be used for 195 restoration. In countries in the recent aftermath of civil wars or natural catastrophes, people who 196 may have lost everything may simply ask for ways to escape the traps of poverty and violence. 197 Whatever comes first with the promise of a better future will quickly be accepted by people, even 198 if it entails new ways of interacting with the natural systems. At this point, conservative views of 199 what restoration is will collide with what people are demanding. For instance, illicit grow of coca 200 (Erythroxylon coca) in South America for the last 40 years has caused degradation of many areas 201 of tropical rain forest in Bolivia, Peru and Colombia, creating social conflicts and violence among 202 peasants that have reduced their quality of life. Because of the difficult climatic conditions and 203 low fertility of tropical forests, agroforestry propositions to replace illegal coca monoculture 204 plantations with a handful of useful native plants are often proposed as an alternative (Corradi et 205 al. 2013). However, local tree diversity can easily exceed 100 tree species per hectare in the 206 western Amazon (Ter Steege et al. 2003), a species richness that will never be attained with 207 agroforestry programs. According to SER standards, this type of restoration would be considered 208 closer to rehabilitation than to ecological restoration (McDonald et al. 2016). Still, using a handful 209 of legal tree crop species may be better than a single, highly polluting crop as coca plants. If the 210 idea of SoER helps local people and external organizations to co-construct a viable future in a 211 respectful manner for both people and natural systems, it may be worthwhile using the concept 212 early in the recovery programs as better biodiversity and social objectives may be attained in the 213 long term. 

programs is the level of external inputs, especially economic inputs (Table S1). Current approaches

216 in ecological restoration seek to assist the recovery process of the relevant ecosystem by allowing

217 for the internal reorganization and adjustments of the system (McDonald et al. 2016). By contrast, 218 highly degraded ecosystems and societies that are a consequence of long-term conflicts or natural 219 catastrophes require immense amounts of external economic input, sometimes for decades. In this 220 regard, the budget allocated to most restoration programs is insignificant compared to the resources 221 committed for recreating stable and self-sustainable human populations. Hence, joining 222 inextricably both social and ecological restoration process, albeit more difficult and costly, may 223 help in the achievement of long-term goals, and hopefully in many cases to ensure sooner the 224 sustainability of human groups in a respectful manner with their environments.

A second external input that may be needed disproportionally in SoER is expertise to 226 recover the traditional ecological knowledge [that is knowledge people have of their environment] 227 that may be endangered or even lost. Community leaders or vulnerable population categories may 228 have fled, lost their leadership or died in areas where social turmoil has been chronic. In this regard, 229 universities, museums and scholars may go along with local communities and participate in SoER 230 programs for recovering disappearing local knowledge.

SoER restoration efforts do not need to start from scratch but can learn from experiences 232 developed and accumulated in programs of community restoration and conservation development. 233 For instance, if the key biodiversity object for restoration identified in the first steps of the SoER 234 cycle is a 'commons' (i.e., resources accessible to everyone and clearly affected by the subtractions 235 of units like trees in a forest or fishes in waterbodies), there is a clear need to acknowledge the 236 complexity associated with governing the commons and avoid top-down out of the box solutions 
237 (Frey \& Berkes 2014; Ostrom 2009). As with community-based conservation principles (Berkes

238 2004), SoER would benefit of building the capacity to deal with multiple objectives and use of 239 deliberative processes (concertation) to allow for a multilayered governance for the various

240 institutions that would get involved in humanitarian crisis and ecosystem restoration (Berkes 2007;

241 Frey and Berkes 2014). This means that contrary to the impression that Figure 1 may give about

242 discrete steps of concertation SoER, deliberation processes to account for the multiple layers of 243 governance and actors will probably be almost permanent.

245 Social-ecological restoration after long term ecological and social degradation

246 As stated earlier, not all SoER programs would be intended for the aftermath of disasters. Until

247 recently, the hunter and horticulturist Shuar people from southern Amazonian Ecuador and 248 northern Peru were a semi-nomadic population. Since the late nineteenth century, Christianization 249 led them to become sedentary, drastically changing their social and political organization as well 250 as their economic life. At present, a large part of their traditional territory is cleared of the original 251 highland Amazonian forest vegetation because of cattle breeding or timber trade, which they 252 adopted to secure titles to their ancestral land to comply with government requirements in the 253 1960’s.

254 Some Shuar communities have initiated family-level restoration programs based on their 255 traditional agroforestry system, the aja (Fig. 2) with a focus on native trees as key stone restoration 256 species (sensu Garibaldi \& Turner 2004). The goal of the aja is to reproduce the high biodiversity 257 of the forest, viewed as the domesticated garden of the master spirit Nunkui were women have the 258 leading role (Descola 1994). Present-day ajas are less diverse than their traditional counterparts 259 and increasingly include Theobroma spp. and Herrania spp. (domesticated and wild cocoa) 
260 because of pressures by exporters looking for rare organic cacao beans that they buy at very low

261 price. This fragile context makes it very easy for some communities to allow mining into their

262 lands or tree felling to make charcoal, as the cash flow is greater and steadier than the difficult

263 market of organic produce for international markets for which they are not prepared. Sadly, the

264 Shuar ignore that cacao trees were certainly domesticated there 5500 years BP (Valdez et al. 2013)

265 and have no means to increase their produce value despite of its importance.

266 Even a superficial needs and assessment analysis (first step of the SoER cycle in Fig. 1)

267 would promptly identify that their rich ecosystem has been degraded to a point where natural 268 regeneration will hardly bring back the biological diversity associated with extirpated late 269 successional trees without external intervention. It is also obvious, that living standards are low 270 and that local knowledge is disappearing fast. People live precariously without running water or 271 sewage and have no one trained at the university level in agronomy or marketing to deal with 272 external markets that appear as the only source of income. Our hypothesis is that engaging the 273 Shuar in a SoER restoration cycle would increase ecosystem health and the Shuar's well-being. 274 For instance, a careful zoning to intermix organic cacao plantations, regeneration plots for late 275 successional tree species and enriched aja gardens for their medicinal and food needs could be a 276 viable option to discuss with them. Such actions would require leadership and local community 277 commitment that is currently wanting, making the dependence on external aid unavoidable. 278 Unfortunately, examples like the Shuar abound worldwide in developing countries and it is 279 difficult to imagine a successful ecological restoration without restoring the links between people 280 and their surrounding nature, even if they include new ways of human-nature interactions. 
283 In sum, we define the emergent concept of Social-Ecological restoration as cycles of reparative 284 processes in which restoring ecosystem function is inextricably linked to repairing basic needs of 285 human populations that depend on a local ecosystem. In general, SoER would be placed in a 286 gradient where humanitarian crises are strong, the dependence on key processes or species within 287 an ecosystem is essential for the local communities, and flexibility regarding the reference 288 ecosystem systems is possible but not mandatory (Fig. 3). In fact, one clear difference between 289 ecosystem service-centered restoration and SoER is that the latter is envisioned as part of a healing 290 process for local populations. In this sense, cultural values associated with ecosystems and the 291 biodiversity contained in them can be as important, or more, than simple recovering plant and 292 animal populations to be exploited by a community in need of income. In fact, communities after 293 a crisis might be living from external input for many years or decades, so that the ecosystem of 294 concern might not be usable for long time. Hence, it is the cultural value and identity they provide 295 that will help people to get afloat again.

We do not argue here in this short essay that all restoration ecology projects should be 297 envisioned as a social-ecological restoration process. In fact, speaking of SoER might even be 298 counter-productive in cases where the links between human welfare and biodiversity are not 299 straight forward. Ecologists and wildlife managers may be frustrated because their roles - and 300 budgets - in SoER may be quite small compared to what is invested in people's recovery, but 301 more ambitious goals may be reached in the long term. The SoER concept can constitute an 302 alternative path in the debate that traditionally opposes the development of human populations and 303 ecological conservation, especially in developing countries where substandard conditions of life 304 are the norm. 
As explained earlier, it will be very unlikely that the term 'restoration' would be used 306 outside of fields related to the ecological sciences because it is awkward when applied to social 307 issues. More general terms, including short and long term reparative actions for both social and 308 ecological components, could be 'social-ecological recovery' and 'social-ecological 309 development', respectively. It is impossible to anticipate which expression will generalize, but any 310 of them could help raising awareness within the humanitarian aid community for calling early the 311 expertise of ecologists and ecosystem managers when handling humanitarian crises.

\section{Acknowledgments}

314 Parts of this research was financed by the LabEX BASC (https://www6.inra.fr/basc) which is a 315 French inter-laboratory initiative for interdisciplinary research on biodiversity, agrosystems, 316 society and climate. We also thank Jilmar Castañeda for providing the photograph included here. 


\section{LITERATURE CITED}

318

319

320

321

322

323

324

325

326

327

328

329

330

331

332

333

334

335

336

337

338

339

340

341

342

343

344

345

346

347

348

349

350

351

Abrahams D (2014) The barriers to environmental sustainability in post-disaster settings: a case study of transitional shelter implementation in Haiti. Disasters 38:S25-S49

Alexander S, Aronson J, Whaley O, Lamb D (2016) The relationship between ecological restoration and the ecosystem services concept. Ecology and Society 21

Alves-Pinto HN, Latawiec AE, Strassburg BBN, Barros FSM, Sansevero JBB, Iribarrem A, Crouzeilles R, Lemgruber L, Rangel MC, Silva ACP (2017) Reconciling rural development and ecological restoration: Strategies and policy recommendations for the Brazilian Atlantic Forest. Land Use Policy 60:419-426

Aronson J, Blignaut JN, Milton SJ, Le Maitre D, Esler KJ, Limouzin A, Fontaine C, De Wit MP, Mugido W, Prinsloo P, Van Der Elst L, Lederer N (2010) Are Socioeconomic Benefits of Restoration Adequately Quantified? A Meta-analysis of Recent Papers (2000-2008) in Restoration Ecology and 12 Other Scientific Journals. Restoration Ecology 18:143-154

Batavia C, Nelson MP (2017) For goodness sake! What is intrinsic value and why should we care? Biological Conservation 209:366-376

Benayas JMR, Newton AC, Diaz A, Bullock JM (2009) Enhancement of Biodiversity and Ecosystem Services by Ecological Restoration: A Meta-Analysis. Science 325:1121-1124

Berkes F (2004) Rethinking Community-Based Conservation. Conservation Biology 18:621-630

Berkes F (2007) Community-based conservation in a globalized world. Proceedings of the National Academy of Sciences of the United States of America 104:15188-15193

Blignaut J, Aronson J (2008) Getting serious about maintaining biodiversity. Conservation Letters 1:12-17

Buckley MC, Crone EE (2008) Negative Off-Site Impacts of Ecological Restoration: Understanding and Addressing the Conflict. Conservation Biology 22:1118-1124

Cao SX (2011) Impact of China's Large-Scale Ecological Restoration Program on the Environment and Society in Arid and Semiarid Areas of China: Achievements, Problems, Synthesis, and Applications. Critical Reviews in Environmental Science and Technology 41:317335

Cao SX, Zhong BL, Yue H, Zeng HS, Zeng JH (2009) Development and testing of a sustainable environmental restoration policy on eradicating the poverty trap in China's Changting County. Proceedings of the National Academy of Sciences of the United States of America 106:1071210716

Corradi CaR, Perugini L, Carbone F, Saenz Moya G, Valentini R (2013) Local cost-benefit analysis for assessing the economic potential of afforestation/reforestation CDM on coca fields in the Peruvian Amazon. Carbon Management 4:387-401 
Day JW, Boesch DF, Clairain EJ, Kemp GP, Laska SB, Mitsch WJ, Orth K, Mashriqui H, Reed DJ, Shabman L, Simenstad CA, Streever BJ, Twilley RR, Watson CC, Wells JT, Whigham DF (2007) Restoration of the Mississippi Delta: Lessons from Hurricanes Katrina and Rita. Science 315:1679-1684

Descola P. (1994) In the society of nature: a native ecology in Amazonia. Cambridge University Press,

Druschke CG, Hychka KC (2015) Manager perspectives on communication and public engagement in ecological restoration project success. Ecology and Society 20:9

Eden S, Tunstall S (2006) Ecological versus Social Restoration? How Urban River Restoration Challenges but Also Fails to Challenge the Science - Policy Nexus in the United Kingdom. Environment and Planning C: Government and Policy 24:661-680

Europeaid. (2004) Project Management Cycles Guidlines. European Commision, EuropeAid Cooperation Office, Brussels

Fox CA, Magilligan FJ, Sneddon CS (2016) "You kill the dam, you are killing a part of me": Dam removal and the environmental politics of river restoration. Geoforum 70:93-104

Frey JB, Berkes F (2014) Can partnerships and community-based conservation reverse the decline of coral reef social-ecological systems? International Journal of the Commons 8:26-46

Garibaldi A, Turner N (2004) Cultural Keystone Species: Implications for Ecological Conservation and Restoration. Ecology and Society 9

Geist C, Galatowitsch SM (1999) Reciprocal model for meeting ecological and human needs in restoration projects. Conservation Biology 13:970-979

Halme P, Allen KA, Aunins A, Bradshaw RHW, Brumelis G, Cada V, Clear JL, Eriksson AM, Hannon G, Hyvarinen E, Ikauniece S, Irsenaite R, Jonsson BG, Junninen K, Kareksela S, Komonen A, Kotiaho JS, Kouki J, Kuuluvainen T, Mazziotta A, Monkkonen M, Nyholm K, Olden A, Shorohova E, Strange N, Toivanen T, Vanha-Majamaa I, Wallenius T, Ylisirnio AL, Zin E (2013) Challenges of ecological restoration: Lessons from forests in northern Europe. Biological Conservation 167:248-256

Mcdonald T, Gann GD, Jonson J, Dixon KW (2016) International Standards For The Practice Of Ecological Restoration - Including Principles And Key Concepts. Pages 48. SOCIETY FOR ECOLOGICAL RESTORATION

Nagendra H, Ostrom E (2014) Applying the social-ecological system framework to the diagnosis of urban lake commons in Bangalore, India. Ecology and Society 19

Ostrom E (2009) A General Framework for Analyzing Sustainability of Social-Ecological Systems. Science 325:419-422 
Palamar C (2010) From the Ground Up: Why Urban Ecological Restoration Needs Environmental Justice. Nature + Culture 5:277-298

Schroter M, Van Der Zanden EH, Van Oudenhoven APE, Remme RP, Serna-Chavez HM, De Groot RS, Opdam P (2014) Ecosystem Services as a Contested Concept: A Synthesis of Critique and Counter-Arguments. Conservation Letters 7:514-523

Takeuchi K, Elmqvist T, Hatakeyama M, Kauffman J, Turner N, Zhou D (2014) Using sustainability science to analyse social-ecological restoration in NE Japan after the great earthquake and tsunami of 2011. Sustainability Science 9:513-526

UNDG. (2007) Joint Guidance Note on Integrated Recovery Planning using Post Conflict Needs Assessments and Transitional Results Frameworks. United Nations Development Group, World Bank

Uprety Y, Asselin H, Bergeron Y, Doyon F, Boucher JF (2012) Contribution of traditional knowledge to ecological restoration: Practices and applications. Ecoscience 19:225-237

Valdez F, De Saulieu G, Julliard G, Lara C. (2013) Primeras Sociedades de la Alta Amazonía: La Cultura Mayo Chinchipe-Marañón. Institut de Recherche pour le Développement-IRD, Quito

Vira B, Adams WM (2009) Ecosystem services and conservation strategy: beware the silver bullet. Conservation Letters 2:158-162

Winkel G (2014) When the pendulum doesn't find its center: Environmental narratives, strategies, and forest policy change in the US Pacific Northwest. Global Environmental ChangeHuman and Policy Dimensions 27:84-95

Yin RS, Zhao MJ (2012) Ecological restoration programs and payments for ecosystem services as integrated biophysical and socioeconomic processes-China's experience as an example. Ecological Economics 73:56-65

\section{Supporting Information}

The following information may be found in the online version of this article:

Appendix S1. Additional details on the humanitarian cycle programs and ecological restoration standards.

Table S1. Synopsis of humanitarian cycle programs and their similarities with restoration ecology programs. 
417 Table 1. Main differences between ecological restoration and social-ecological restoration based on six principles of ecological restoration (McDonald et al., 2016).

419

\section{Key}

Ecological restoration

Social-ecological restoration (SoER)

concept

1 Practice is based on an appropriate local native The target system can be a highly reinterpreted reference ecosystem, taking environmental reference system; the new system typically builds change into account. resilience to floods, fires, etc. and could be seen as rehabilitation or even as ecological engineering. External market opportunities may cause local people to switch to new ways of interacting with their ecosystems and the species that they collect or gather.

2 Identifying the target ecosystem's key attributes In addition to identifying the ecosystem's (threats, physical conditions, species attributes, SoER programs may need to address composition, structural diversity, and ecosystem functions and flows with other ecosystems) is required prior to developing longer-term goals as security, political participation, and the end of and shorter-term objectives. violence, among others.

3 The most reliable way to achieve recovery is to In contrast to letting the system self-organize, assist natural recovery processes, while supplementing them to the extent that natural recovery potential is impaired. the level of people's vulnerability and their access to food, shelter, and basic goods, as well violence, among others.

massive external economic inputs may influence the trajectory of the system in very short periods of time, which is common in humanitarian crises. 
Restoration seeks the "highest and best effort"

towards full recovery; the recovery can be quantified for each of the key attributes (see principle 2).

5 Successful restoration draws on all relevant knowledge.

6
Full recovery is rarely known for SoER in countries with civil wars, as they may be recurrent crisis because of poverty and violence traps.

Relevant knowledge may have been lost if key actors have died or fled from the target regions.

Long periods of time may be needed until all actors are actively engaged, thus making the SoER process probably longer than equivalent ecological restoration programs.

421 Table S1. Synopsis of humanitarian cycle programs and their similarities with restoration

422 ecology programs as currently conceptualized by leading institutions in the area. Humanitarian

423 aid is highly coded regarding steps and mandatory documents to comply with international

424 funding agencies and governments. Synthesis steps from both fields are outlined as a set of

425 simple questions in the Social-Ecological restoration cycle proposed in Figure 1 in the main text.

426

\begin{tabular}{lll}
\hline $\begin{array}{c}\text { Stag } \\
\text { e }\end{array}$ & Humanitarian program cycle & $\begin{array}{c}\text { Standard practices for planning and implementing } \\
\text { ecological restoration projects }^{2}\end{array}$ \\
\hline 1 & Needs, assessment \& analysis & 1.1 Stakeholder engagement \\
& \multicolumn{3}{l}{ In humanitarian contexts, two main } & 1.2 External context assessment \\
assessments are produced, a & \\
& $\begin{array}{l}\text { Humanitarian Needs Overview } \\
\text { (HNO) to gather the necessary }\end{array}$ & \\
& $\begin{array}{l}\text { evidence, and a severity ranking of } \\
\text { the different threats that are }\end{array}$ & \\
summarized in a Humanitarian & \\
Dashboard, which is a simple to & \\
\hline
\end{tabular}


understand document that can be shared with all levels of authorities

$2 \quad$ Strategic response planning

Humanitarian response plans (HRPs) are required for any humanitarian crisis requiring the support of more than one agency, and are prepared by country level teams based on the humanitarian needs overview (HNO) from the previous step.

The HRPs consist of: 1. a country strategy consisting of a narrative, strategic objectives and indicators, and, 2. cluster plans consisting of objectives, activities and accompanying projects, which detail implementation and costing of the strategy.
1.5 Targets, goals and objectives

1.6 Restoration treatment prescription

1.7 Assessing security of site tenure and of post treatment maintenance scheduling

\section{Resource mobilization}

It is recommended that humanitarian aid implement a Financial Tracking Service (FTS) to provide data aggregation and curation service for funding and a unique, open data platform for visibility and transparency. It is a special branch of the United Nations Office for the Coordination of Human Affairs (OCHA). Funds are pooled at the global or at the country level
1.8 Analyzing logistics

1.9 Review process scheduling 


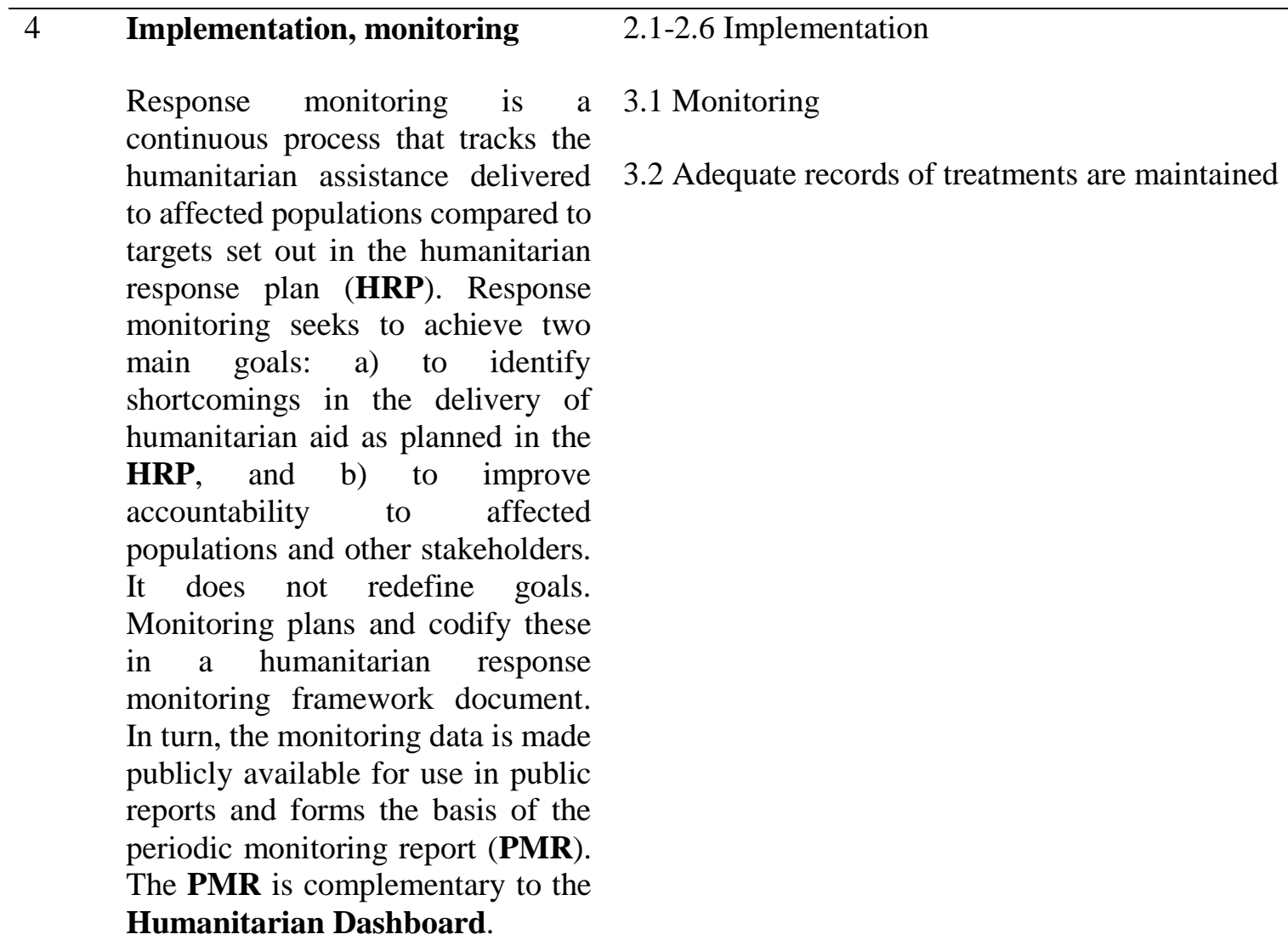

$428{ }^{1}$ Text adapted from https://www.humanitarianresponse.info/en/programme-cycle/space

$429 \quad{ }^{2}$ Text adapted from SER standards 2016 